\title{
The Effect of Self, Peer and Teacher Correction on the Pronunciation Improvement of Iranian EFL Learners
}

\author{
Saeideh Ahangari \\ Department of English, College of Farsi Literature and Foreign Languages, Tabriz Branch, Islamic Azad University, Tabriz, Iran \\ E-mail: Ahangari@iaut.ac.ir; s_ahangari@yahoo.com
}

Doi:10.7575/aiac.alls.v.5n.1p.81

URL: http://dx.doi.org/10.7575/aiac.alls.v.5n.1p.81
Received: 02/01/2014

Accepted: 28/02/2014

\begin{abstract}
The concept of self correction and peer correction in foreign language teaching has been an important consideration in the past decades due to the increased attention to learner centered curricula. The researchers have concluded that active engagement happens when the students have to think and correct themselves. The purpose of this study was to investigate the effect of teacher, self and peer correction on the pronunciation improvement of Iranian EFL learners in oral productions. To do this, 45 participants were selected from among 60 English language learning students by assigning a PET test and they were divided into three groups. Some picture series were given to the participants to make and then tell a story based on the scripts. In the self correction group every participant had to correct her pronunciation errors individually, in the peer correction group the participants in pairs corrected each others' pronunciation errors and for the third group their errors were corrected by the teacher. This process continued for 15 sessions. A pre-test and post-test were administered. The results showed that the pronunciation of the self correction group improved more than the other two groups and peer correction group outperformed the teacher correction group.
\end{abstract}

Keywords: pronunciation, self correction, peer correction, teacher correction

\section{Introduction}

A conceptual shift which has occurred in recent times in higher education has been from a perspective which focused on the teacher, to a perspective in which student involvement is more central (Boud,1995). The recent literature on language learning from constructivist perspective has indicated that knowledge is not attained but constructed (von Glasersfeld 1989, cited in Kim 2005) by learners, which implies that different learners construct their own meanings. The concept of self-correction and peer correction in foreign language teaching and learning has been an important consideration in the past decades. This practice is supported by both pedagogic and other findings. Lyster and Ranta(1997) in an inspection conclude that student-generated repairs and editing are important factors in language learning because they indicate active engagement in the learning process. This active engagement happens when there is a negotiation of form, or when the students have to think and correct themselves.

Humanistic psychology and cognitive psychology both attest the significance of meaningful learning, that is, a learning experience in which the learner is made emotionally interested and cognitively engaged. With this realization, effort was made, in language pedagogy, to search for methodological proposals that would engage the learners emotionally and promote meaningful learning.

The use of tasks in language teaching was introduced as such a proposal in which, according to Nunan (1989, cited in Ellis, 2003), represents the transformation of ideas from the linguistic knowledge or the skills to be mastered to what learners need to do in order to learn, from the outcomes of instruction towards the processes of learning. Task based activities have been defined comprehensively by Willis (2003). In his idea a task is a work plan and makes a plan to develop learning and also involves a primary focus on meaning. It seeks to develop L2 proficiency through L2 proficiency. Tasks involve real world process of language use and may require learners to engage in a language activity such as that found in a real world and can involve any one of language skills. With the emergence of TBLT, learning activities were no longer described merely in terms of inventories of language items, but also, and most importantly, in terms of tasks that could be accomplished during the class time to engage learners in some meaningful activities.

Regarding the impact of self-correction and peer correction on learning, our challenge has been to investigate the role of self-correction and peer-correction in the task-based context in promoting EFL (English as Foreign Language) learners' pronunciation. Yet, it seems pertinent that prior to discussing teacher, self- and peer correction, a brief look be taken at some theories about speech production and pronunciation.

\section{Review of related Literature:}

Pronunciation teaching is an essential part of any language teaching process. On the one hand, confidence with pronunciation allows learners to interact with native speakers that is so essential for all aspects of their linguistic development. On the other hand, poor pronunciation can mask otherwise good language skills condemning learners to 
less than their deserved social, academic and work advancement. People from different countries of the world are now working and living in a global village. "Labor mobility and the existence of internationally employment opportunities have heightened the need to communicate and to be understood" (Mitra, Tooley, Inamdar, \& Dixon, 2003, p.2). Good pronunciation is closely linked with clear oral communication: therefore, it is advisable to place students in a meaningful and contextual situation, and involve them in performing of the real-like tasks. Recently as the curricula of English language teaching has moved towards communicative competence and task-based language teaching, a new urgency for the teaching of pronunciation has arisen (Celce-Murcia, 1987), because poor pronunciation will causes problems in oral communication, no matter how well a speaker's control of vocabulary or grammar might be.

Approaches to second language teaching have traditionally attributed a primary role to feedback, whether generated by learner, a peer, a computer, or a teacher and whether occurring through error correction, self editing, peer feedback, or conferencing (Hylland \&Hylland, 2006). The importance of feedback emerged with the development of learner centered approaches to writing instruction in North American L1 composition classes during the 1970s. The "process approach" gave greater attention to support writers through multiple drafts by providing feedback and suggesting revisions during the process of writing itself, rather than at the end of it.

Feedback refers to the response that learners receive regarding the language they produce (VanPatten and Benati, 2010). Feedback is a natural part of language that we use to clarify the meaning of what we say, and to help ourselves and others understand what we mean, by asking questions (Ferm Lange, 2009). The form feedback takes is extended beyond the teacher's marginal notes to include oral interaction involving the teacher or the students themselves. The focus moves from a concern with mechanical accuracy and control of language to a greater emphasis on the development and discovery of meaning through the experience of speech production and reproduction. Feedback comes to be viewed as having a powerful potential, with the potentiality for "a revision of cognition itself that stems from response" (Freedman, 1985, p.6).

Feed back and correction have mainly been investigated in the writing classes. For example, according to Hyland and Hyland (2006) providing feedback to students has come to be recognized as one of the ESL writing teacher's most important tasks. It can be in the form of "written commentary, error correction, teacher-student conferencing, or peer discussion" (p.xv). It offers the kind of individualized attention that is otherwise rarely possible under normal classroom conditions. Feedback as viewed by Magno and Amarles (2011) necessitates the existence of gaps between what has been learned and the target competence of the learners, and the efforts undertaken to bridge these gaps. The role of feedback and correction; however, has not been properly touched in the area of speech production and pronunciation improvement of foreign language learners.

\subsection{Teacher Correction}

Regardless of pedagogical approach (traditional product-based, process-oriented, or genre-based), the response of teachers to student performance has been examined in a variety of ways. Depending on the type of the feedback, teacher feedback has been found sometimes to help, to hinder, and occasionally to have no effect on students' learning and revising (Silva \& Brice, 2004). Kazuya (2011), for example, investigated the acquisitional value of form-focused instruction (FFI) with and without corrective feedback (CF) on 65 Japanese EFL learners' pronunciation development. The results showed that: F3(third formant) values of the FFI + CF group significantly declined after receiving corrective feedback, not only at a controlled-speech level but also at a spontaneous-speech level, regardless of following vowel contexts.

Kazuya (2013) in another study investigated the impact of form-focused instruction on L2 pronunciation development. The results of the ANOVAs showed that (a) the FFI-only group demonstrated moderate improvement with medium effects and (b) the FFI+EI (explicit information) group not only showed considerable improvement with large effects but also generalized the instructional gains to unfamiliar lexical contexts beyond the instructional materials.

Hedgcock (2005) suggested that the effects of teacher feedback depend on several factors such as learners' proficiency levels, their educational needs and expectations, curricular and institutional constraints, the nature of tasks, the focus of teacher commentary, and learner training. Surveys of students' feedback preferences generally indicate that ESL students greatly value teacher feedback and consistently rate it more highly than alternative forms such as peer and oral feedback (Ferris 1995; Hyland \& Hyland, 2006). Teacher correction will be quicker, more effective and accurate. Despite students' preferences of teacher corrective feedback, its contribution to students' language improvement is still controversial. It may fail to encourage students' independence and they may feel embarrassed when corrected by the teacher. So some researches propose other types of corrective feedback, such as self correction and peer correction.

\subsection{Peer Correction}

In the last two decades, an alternative to teacher corrective feedback has appeared to be put into practice by L2 teachers and has closely been investigated by second language acquisition researchers under the general rubric of peer review. From a socio-cognitive perspective, peer review can be seen as a formative developmental process that gives learners the opportunities to discuss their productions and discover theirs' interpretations of them (Hyland \& Hyland, 2006). According toMcDowell (1995), the main strengths of peer feedback are that (1) there is a development of evaluative and critical abilities, (2) there are opportunities for skill development, (3) knowledge is more integrated and (4) students collaborate, are motivated and are satisfied. It is assumed that knowing the criteria of a product and observing the work of peers, leads to a higher understanding of the quality of one's own work (Falchikov, 1995; Freeman, 1995).Peer correction is seen as a way of giving more control to students since it allows them to make active decisions about 
whether or not to use their peers' comments as opposed to a passive reliance on teachers' feedback ( Mendonca \& Johnson, 1994 ; Mittan, 1989).Freedman and Sperling (1985) and Mittan (1989) consider that peer response can be more authentic and honest than teacher response. It encourages the atmosphere of cooperation and makesthe other students stay involved in the lesson.

Some research projects such as (Hagege, 1996) have suggested that correction is even more efficient when it is done with the help of peers. Yurick and collegues (2006), for example, conducted three experimental studies to investigate the impact of peer-mediated oral RRS on students' fluency and pronunciation. Their findings showed improvement in the fluency and pronunciation of the students due to peer mediation. Tost (2013) also evaluated the feasibility and impact of partner reading out aloud to improve English pronunciation, fluency and expression. Her findings indicated that peer- mediated repeated oral reading interventions done by students' cooperation was effective in improving their levels of reading pronunciation and fluency.

Some others like Chaudron (1984) has found the influence of teacher and peer feedback on writing improvement to be about the same, while,other researchers such as Zhang (1985) found teacher feedback as more effective than peer feedback in the improvement of grammatical errors. Peer feedback has been suggested to suffer from certain problems including: firstly, "student editors are more likely to address surface errors and not the problems of meaning" (Keh, as cited in Hyland \& Hyland, 2006); also "the inexperienced students may find it hard to judge the validity of their peers' comments" (Leki, as cited in Hyland \& Hyland, 2006); finally, students might have difficulty identifying problem areas in their peers' performance and offer them misleading advice" (Horowitz, as cited in Hyland \& Hyland, 2006). Therefore, there is still a need for further investigation of the effectiveness of the peer feedback and correction.

\subsection{Self Correction}

In most educational systems today, one of the basic pedagogical principles is that good conditions for learning are best achieved if learners are actively involved in all phases of the educational process, which is maintained by proponents of cognitive and constructive theories of learning ( e.g. Cobb, 1994; Von glasersfed, 1995, cited in Birjandi \& Hadid, 2011). Self along with peer correction is also valued in the teaching process. Buchanan (2004) acknowledges that self correction can be a force that pushes students to engage more actively in their own learning process. Shunk(2000, cited in Buchanan) also states that, " developing self and peer evaluation strategies help students gain control over their learning, ....and allows them to focus more effort in studying those areas where they need more time" (p. 379).

Involving the students in correcting of their own errors give them confidence and helps them to be the judges of their own performances. Kavaliauskiene (2003) has stated that learners must have the opportunity for the self-correction of their work individually; however, their work should be previewed by the teachers and their errors should be indicated. Marie Wood (2004) at the University of Kansas found that students enjoyed looking back at their composition and compare their first performance with the second.

While enough conceptualization has already been made about teacher feedback, and a good number of experimental studies have been conducted to examine the effect of peer feedback on different aspects of second language learning, there are limited reflection and research studies that have compared the effect these three types of correction on the improvement of EFL learners' pronunciation sub-skill. The research so far has not been conclusive on the central issue of which type of feedback and correction is an effective means of improving L2 performance. So inspired by the reviewed literature, the researcher intended to investigate the impact of the three types of feedback and correction, i.e. teacher, self and peer on the improvement of Iranian EFL learners' pronunciation. To do so the researcher raised the following questions:

\subsection{Research Questions}

1-Does self-correction have any significant impact on the improvement of EFL learners' pronunciation?

2- Does peer-correction have any significant impact on the improvement of EFL learners' pronunciation?

3- Are there any differences among three groups (control and two experimental groups) regarding the improvement of their pronunciation?

\section{Methodology}

\section{1 participants}

The participants were 45 female students who were studying English as a foreign language in a language institute in Tabriz, Iran .The age range of the participants was fifteen to twenty and all of them were pre-intermediate English students. The study was conducted in the first semester of 2012 academic year. Participants were selected from intact classes but they were randomly divided into three groups. The first group was considered as the control group and for this group teacher corrected their errors and other two groups were considered as experimental groups for which peer correction and self correction techniques were provided. The homogeneity of the participants in terms of their L2 language proficiency was assured through Preliminary English test (PET).

\subsection{Instrumentation}

\subsubsection{Preliminary English Test (PET)}

The Preliminary English Test which was used to examine the participants ' English language proficiency at the beginning of the study is an international examination sanctioning a certain level of English mastery of the English 
language. The preliminary English Test (PET) is a second level Cambridge ESOL exam for the intermediate level learners.

\subsubsection{Story telling tasks}

The participants had to perform a narrative task by telling a story based on a set of pictures taken from Heaton (1975).

\subsection{Procedure}

The study with a quasi-experimental design, started with the administration of proficiency test PET to 60 female students who were studying English at language institute. Forty five students out of sixty who received one standard deviation above and under the mean were selected as the participants of the study. Based on the results, the participants were divided into three groups and ANOVA analysis was used to test homogeneity of the participants .The second step was assigning a pretest: A series of pictures taken from Heaton (1975) were given to students to make and tell a story based on the pictures and the performance of the participants were recorded and then scored.

During the treatment period which lasted for a semester all groups performed narrative tasks, but each group received a different type of feedback. In the self correction group, while each participant was performing a task, the teacher used to take notes and write down that participant's pronunciation errors. After finishing of the task, the teacher was giving her notes to the participant and asked her to find the correct pronunciation of the mentioned words and learn their correct form. In the following session each participant had to tell the same story, but with the correct pronunciation. The second experimental group worked in a team frame which included two participants and they corrected each others' pronunciations. In this group, while one of the pairs was performing the task, the other pair had to take notes and find her friend's pronunciation errors. She was also responsible for finding of the correct pronunciation of the mentioned words and sharing them with her pair. For the last group which was considered as the control group the teacher corrected the participants' pronunciation errors while they were performing the task. After three months the researcher administered a post test. For the post test again a set of pictures was given to the participants, and they had to make and tell a story based on the pictures.

The participants' performances were recorded and scored by two raters and inter rater reliability index was calculated for two sets of scores. For measuring of the participants' pronunciation, the data coded for the total number of the produced words and it was reflected by calculating error free words per total number of the words.

\section{Data Analysis and Results}

\subsection{Investigating the Homogeneity of the Participants in Three Groups Regarding Their General Proficiency}

As it has been mentioned before, the participants of this study were selected from among 60 EFL students based on their proficiency scores. Then they were divided into three identical groups. In order to check their homogeneity, a one way ANOVA was run on their proficiency scores. As it is clear from table 1, the mean score of three groups are approximately the same $(68.73,68.27,66$, and 80$)$. But in order to be sure whether there is any significant difference among the mean score of the three groups or not, the data were analyzed through a one-way ANOVA; the results of which are shown in table 2.

Table 1. Descriptive statistics for PET test

\begin{tabular}{llllll}
\hline Groups & $\mathrm{N}$ & Mean & Std. Deviation & Minimum & Maximum \\
& & & & & \\
\hline self correction & 15 & 68.73 & 3.731 & 63 & 75 \\
peer correction & 15 & 68.27 & 4.891 & 61 & 75 \\
teacher correction & 15 & 66.80 & 3.256 & 62 & 73 \\
Total & 45 & 67.93 & 4.014 & 61 & 75 \\
\hline
\end{tabular}

Table 2. One-way ANOVA for pet test

\begin{tabular}{lllllll}
\hline & & Sum of Squares & $\mathrm{df}$ & Mean Square & F & Sig. \\
\hline PET & Between Groups & 30.533 & 2 & 15.267 & .945 & .397 \\
& Within Groups & 678.267 & 42 & 16.149 & & \\
& Total & 708.800 & 44 & & & \\
\hline
\end{tabular}

As the results of the ANOVA test in table 2 shows, there has not been a significant difference among the three groups regarding their proficiency level $(\mathrm{F}(2,42)=0.945, \mathrm{p}=0.397)$. 


\subsection{Discussion of Variables' Scores Dispersion Normality}

The data obtained from the performance of the participants in the narrative tasks were put into SPSS and one-Sample Kolmogorov-Smirnov Test (table 3) was run to test the normality of scores dispersion. Assuming zero shows the normality of the variables dispersion. If significance level be under 0.05 , then the zero will be denied and the result of the dispersion normality is not acceptable.

Table 3. One-Sample Kolmogorov-Smirnov Test

\begin{tabular}{lllll}
\hline & Group & $\mathrm{N}$ & $\begin{array}{l}\text { Kolmogorov- } \\
\text { Smirnov Z }\end{array}$ & $\begin{array}{l}\text { Asymp. Sig. } \\
\text { (2-tailed) }\end{array}$ \\
\hline Pre-test & self correction & 15 & .510 & .957 \\
& peer correction & 15 & .506 & .960 \\
& teacher correction & 15 & .635 & .814 \\
\multirow{2}{*}{ Post-test } & self correction & 15 & 1.069 & .203 \\
& peer correction & 15 & .703 & .706 \\
& teacher correction & 15 & .496 & .967 \\
\hline
\end{tabular}

Based on the results of One-Sample Kolmogorov-Smirnov Test, shown in table 3 the normality of the scores in pre-test and post-test was assured and the following tests were computed for answering the research questions.

\subsection{Comparison of the of the pretest and posttest scores for the self-correction group}

To answer the first research question a paired sample T-test was conducted to see if there is any significant difference in the pronunciation scores of the pretest and posttest for self-correction group.

Table 4. Paired Samples T-Test for the self correction group

\begin{tabular}{|c|c|c|c|c|c|c|c|c|}
\hline Group & & & Mean & $\mathrm{N}$ & $\begin{array}{l}\text { Std. } \\
\text { Deviation }\end{array}$ & $\mathrm{T}$ & $\mathrm{Df}$ & $\begin{array}{l}\text { Sig. (2- } \\
\text { tailed) }\end{array}$ \\
\hline \multirow{2}{*}{$\begin{array}{l}\text { self } \\
\text { correction }\end{array}$} & \multirow[t]{2}{*}{ Pair 1} & Pre-test & .587 & 15 & 0.128 & \multirow[t]{2}{*}{-8.515} & \multirow[t]{2}{*}{14} & \multirow[t]{2}{*}{.000} \\
\hline & & Post-test & .876 & 15 & 0.094 & & & \\
\hline
\end{tabular}

As table 4 shows the pronunciation mean score for the self correction group in the posttest is bigger than the pretest and significance level is smaller than 0.05 ( $\mathrm{t}(14)=-8.515, \mathrm{p}=0.000)$, so we can conclude that the pronunciation measurement in the self correction group has shown a significant increase. So the answer to the first question is positive.

\subsection{Comparison of the Pretest and Posttestscores for the peer-correction group (Question 2)}

To answer the second research question a paired sample t-test was used to see if there is any difference in the pronunciation scores of the pretest and post test for the peer correction group, the results of which are shown in table 5 .

Table 5. Paired Samples T-Test for the peer-correction group

\begin{tabular}{|c|c|c|c|c|c|c|c|c|}
\hline Group & & & Mean & $\mathrm{N}$ & Std. Deviation & $\mathrm{t}$ & $\mathrm{df}$ & Sig. (2-tailed) \\
\hline \multirow{2}{*}{$\begin{array}{l}\text { Peer } \\
\text { correction }\end{array}$} & \multirow[t]{2}{*}{ Pair 1} & Pre-test & .615 & 15 & 0.112 & \multirow[t]{2}{*}{-3.757} & \multirow[t]{2}{*}{14} & \multirow[t]{2}{*}{.002} \\
\hline & & Post-test & .736 & 15 & 0.066 & & & \\
\hline
\end{tabular}

As it is clear from the table 5, the mean of the pronunciation scores in the posttest (.736) is bigger than pretest (.615) and significance level is smaller than $0.05(\mathrm{t}(14)=-3.757, \mathrm{p}=0.002)$, So the answer to the second question is positive and we can say that peer correction leads to more improvement in the pronunciation of the participants.

\subsection{Comparison of pronunciation scores among three groups in posttest (Question3)}

Based on the third research question, the researcher wanted to find out if there is any significant difference among the three groups regarding their pronunciation scores in the post-test. To answer this question the researcher conducted a one way ANOVA analysis. Assuming zero shows that there is no difference between two variables. If the significance level be under 0.05 then the zero assuming will be denied. Table 6 shows the descriptive statistics in three groups. The variances equality in the three groups is needed for testing of the means. So this test is done by Levene statistics. 
Table 6. Descriptive \& Test of Homogeneity of Variances

\begin{tabular}{lllllllll}
\hline & Group & $\mathrm{N}$ & Mean & Std. Deviation & Levene Statistic & df1 & df2 & Sig. \\
\hline Post-test & self correction & 15 & .876 & .094 & 2.431 & 2 & 42 & .100 \\
& peer correction & 15 & .736 & .066 & & & \\
& teacher correction & 15 & .623 & .110 & & & \\
& Total & 45 & .745 & .138 & & & \\
\hline
\end{tabular}

As it is indicated in table 6, the mean score of self-correction group (0.876) is higher than the other groups and the mean score of the peer correction group (0.736) in turn is more than the mean score of the teacher correction group which is 0.623 .

In order to see whether this difference among the groups is statistically meaningful or not, the researcher conducted a one-way ANOVA test, the results of which are shown in table 7.

Table 7. ANOVA test for the comparison of groups

\begin{tabular}{lllllll}
\hline & & Sum of Squares & df & Mean Square & F & Sig. \\
\hline Post-test & Between Groups & .481 & 2 & .241 & 28.360 & .000 \\
& Within Groups & .356 & 42 & .008 & & \\
& Total & .837 & 44 & & & \\
\hline
\end{tabular}

As the results of ANOVA test $(\mathrm{F}(2,42)=28.36, \mathrm{p}=0.000)$ in table 7 shows, the difference across the participating groups' pronunciation measurement reached significance.

The values observed for the $\mathrm{F}$ and $p$ value indicated that the three groups involved did not perform equally in the narrative task performance, because of the different types of correction they have had for their pronunciations.

To statistically identify the location of this difference, a post-hoc Tukey was also run. The results of Tukey HSD analysis are represented in table 8.

Table 8. Tukey HSD

\begin{tabular}{lllll}
\hline (I) Group & (J) Group & Mean Difference (I-J) & Std. Error & Sig. \\
& & & & \\
\hline \multirow{2}{*}{ self correction } & peer correction & $.139600^{*}$ & .033628 & .000 \\
& teacher correction & $.252800^{*}$ & .033628 & .000 \\
\multirow{2}{*}{ peer correction } & teacher correction & $.113200^{*}$ & .033628 & .005 \\
\hline
\end{tabular}

As the results of table 8 indicates the pronunciation mean score of posttest in self-correction group significantly is bigger than peer correction and teacher correction groups. Likewise, the pronunciation means score of the posttest in peer correction group is significantly bigger than the teacher correction (control group).

\section{Discussion}

The results showed that there was a significant difference among the means of the participants of three groups regarding their pronunciation during the narrative task performance. The self correction group had the highest mean in the posttest, while the peer correction group outperformed the control group but had a mean score less than the self correction group.

The findings of the present study are consistent with Lyster and Ranta(1997) findings that student repair and correction leads to better language learning. They concluded that active engagement happens when there is a negotiation of form and focus on the form. The noticing hypothesis (Schmidt, 1990) claims that Second language learners could not begin to acquire a language feature until they had become aware of it in the input and also they should notice the grammatical form of their input in order to acquire grammar. In the present study the participants who had corrected their own errors paid more attention to those errors and learned them better than the other group participants. The findings support Buchanan (2004) acknowledgement that self assessment can promote more active engagement with the course than simply sitting back and waiting for a grade. The results are also in line with the statements of Schunk (2000, cited in Buchanan, 2004) who says that developing self evaluation strategies help students gain control over their learning.

These findings are also in line with the findings of Wood (2003) at the University of Kansas. She studied the benefits of self-correction in her own class during two months and concluded that students enjoyed looking back at their compositions and errors provide wonderful opportunities for learning and improving their written language. Yeganehfar 
(2000) also argues that as far as responding to the written errors of Iranian EFL students is concerned, students' selfcorrection works much better than teacher correction.

Self correction involves the students in the process of language learning, and it renews their confidence if they can correct themselves. It makes their mistakes more memorable and less likely to occur. Students' self correction also informs teacher about the students' knowledge, ability and awareness.

Hagege (1999) believes that correction is even more efficient when it is done with the help of children's classmates, even though in the present study the self correction group outperformed the peer correction group. The peer correction group showed more improvement compared to the control group, which received the teacher correction feedback. The better performance of this group as compared to the teacher correction group is in line with Vygotsky's (1978) theory on language learning, i.e., learning is a cognitive activity which takes place in social interaction. Ganji (2006, cited in Birjandi \& Hadidi, 2011) also expresses that peer-correction seems to have a more lasting effect on the learners' performance, due to the need for more cooperation and activity on the part of the learners, while analyzing and discussing the errors in more details. In this regard the findings of the present study are in agreement with those of Tost (2013) who concluded that peer-mediated repeated oral reading interventions carried out by students' cooperation was effective in improving of the students' pronunciation and fluency.

\section{References}

Birjandi, p. \& Hadidi, Tamjid, N. (2011). The role of self, teacher and peer assessment in promoting Iranian EFL learners' writing performance. Assessment and Evaluation in Higher Education, 1-21.

Buchanan, E.A. (2004). Online assessment in higher education. Strategies to systematically evaluate student learning. In C. Howard, K. Schenk, \& R. (EDS.). Distance learning and university effectiveness: Changing educational paragdims for online learning. (pp. 68 -117). Hershey, P.A: information Science Publishing.

Celce-Murcia, M. (1987). Teaching pronunciation as communication. In J, Morley. (ED) Current perspectives on pronunciation. Washington DC: TESOL.

Chaudron, C. (1984). The effects of feedback on students' composition revisions RELC Journal, 15(2), 1-15.

Cobb, P. (1994). Where is the mind? Constructivist and sociocultural perspectives on Mathematical development. Educational Researcher 23, no. 7: 13-20. http://edr.sagepub.com/content/23/7/13. Retrieved, September 20, 2012.

Connor, U. and K. Asenavage, (1994). "Peer response groups in ESL writing classes: How much impact on revision?". Journal of Second Language Writing. 3 (3): 257-276, 1994.

Ellis, R. (1991). Second language acquisition a language pedagogy. Clevedon: Multilingual Matters

Ellis, R. (2003). Task-based language learning and teaching. Oxford: Oxford University Press.

Ferm Lange, C. (2009). Corrective Feedback during communicative activities: A study of recasts as a feedback method to correct spoken English (Unpublished doctoral dissertation). Karlstads University, Linköping.

Ferris, D. (1999). The case for grammar correction in L2 writing classes: A response to Truscott, 1996. Journal of Second Language Writing, 8, 1-11.

Fotos, S. (1994). Integrating grammar instruction and communicative language use through grammar consciousness raising tasks. TESOL Quarterly, 28, 323-51.

Freedman, S. W. (Ed.). (1985). The acquisition of written language. Response and revision. Norwood, NJ: Ablex.

Freedman, S. \& Sperling, M. (1989). Teacher student interaction in the writing conference: Response and teaching. In S. Freedman (Ed), The acquisition of written language: Response and revision. (106-130). Norwood, NJ: Ablex.

Hagege, C.(1996). "L'enfant aux deux langues" (The child between two languages), Greek translation, Polis editions, Athens 1999. (Original publication: Editions Odile Jacob, 1996).

Heaton, J.B.(1975). Beginning Compositin throughPictures. Greenville: Longman Publication.

Hedgcock, J. (2005). Taking stock of research and pedagogy in L2 writing. In E. Hinkel (Ed.), Handbook of research in second language teaching and learning (pp. 597- 613). Mahwah, NJ: Lawrence Erlbaum Associates.

Hyland, K. \& Hyland, F. (2006). Feedback in second language writing: Contexts and issues. USA: Cambridge University Press.

Kavaliauskiene, G. (2003). Ongoing Needs analysis as a factor to successful language learning. Language and Learning.1 (1).

Kazuya, S. (2012). Effects of form-focused instruction and corrective feedback on L2 pronunciation development by Japenese learners of English. Language Learning, 62-2

Kazuya, S. (2013). Examining effects of form-focused instruction on L2 pronunciation development. Studies in second language acquisition. $35-1$

Kim, J.S. 2005. The effects of a constructivist teaching approach on student academic achievement, self-concept, and learning strategies. Asia Pacific Education Review 6, no. 1: 7-19. 
Lyster, R. \& Ranta, L. (1997). Corrective feedback and learner uptake: Negotiation form in communicative classrooms. Studies in Second Language Acquisition, 19, 37-66.

Magno, C., \& Amarles, A.M. (2011). Teachers' feedback practices in second language academic writing classrooms. The International Journal of Educational and Psychological Assessment, 6(2) 21-30.

Marie Wood, N.(2004).(Self-Correction and Rewriting of Student Compositions: The Correction Code. Bureau of Educational and Cultural Affairs. OFFICE OF ENGLISH LANGUAGE PROGRAMS.

Mendonca, C . \&. Johnson, k. (1994). Peer Review Negotiations: Revision Activities in ESL Writing Instruction. TESOL Quarterly, 28(4), 745-769.

Mitra, S., Tooley, J., Inamdar, P., Dixon, p. (2003). Improving English pronunciation: An automated instructional approach . The Massachusetts Institute of technology Information, Information Technologies and International development, Vol 1, No1

Paulus, T. (1999). The effect of peer and teacher feedback on student writing. Journal of second Language Writing, 8 , 265-289.

Saito, H. (1994). Teachers' practices and students' preference for feedback on second language writing: A case study of adult ESL learners. TESL Canada Journal, 11(2), 46-70.

Schmidt, R. (1990). The Role of Consciousness in Second Language Learning. Applied Linguistics, 11, 129-158.

Silva, T., \& Brice, C. (2004). Research in teaching writing. Annual Review of Applied Linguistics, 24, 70-106.

Skehan,P.(1996). A Framework for the implementation of task based instruction. Applied Lingustic. 17:38-62.

Skehan, P.1998. A Cognitive Approach to Language Learning. Oxford:Oxford University Press.

Tost, G. (2013). Bettering pronunciation through reading aloud and peer appraisal. Bellaterra Journal of Teaching and Learning Language and Literature. 6-1.

VanPatten, B., \& Benati, A. G. (2010). Key terms in second language acquisition. London: Continuum.

Vygotsky, L. (1978). Mind in society: Interaction between learning and development. Cambridge: MA. Harvard University Press.

Willis,D. an J. Willis.2003.Task -based Language .In R.Carter and D.Nunan(eds). The Cambridge Guide to Teaching English to Speakers of Other languages. Cambridge: Cambridge University Press.

Yurick, A.L., Robinson, P.D., Cartledge G., Lo, Y. \& Evans, T.1.(2006). Using peer mediated reading as a fluency building activity for urban learners. Education and Treatment of Children, 29-3

Zhang, S. (1985). The difference effects of source of corrective on ESL writing proficiency. Occasional paper series no 9. Honolulu: University of Hawaii at Manoa, Department of English as a Second Language. 